\title{
6. DEVELOPMENT OF METHODS
}

The New South Wales Child Health Survey was conducted in the NSW Department of Health's 19-station computer assisted telephone interviewing (CATI) facility, which was used to administer the 1997, and 1998 NSW Health Surveys of adults, ${ }^{22}$ and 1999 Older People's Survey. ${ }^{60}$ More than 95 per cent of people in NSW have a telephone in their household, making CATI interviewing an efficient, reliable, and safe method of collecting information for population surveys. ${ }^{5}$ Methods were mostly consistent with previous NSW Health Surveys, ${ }^{22}$ except for methods of sampling of children, use of proxy respondents, introductory questions, and bi-lingual interviews.

\section{Sampling and over sampling}

A two-stage random sampling process was used to sample children, involving random selection of a household followed by random selection of a child aged 0-12 years in the household. The total sample size was 8,500 respondents and was stratified by area health service such that 500 children would be surveyed in each of the 17 area health services in NSW. The expected sample size for each year of age for each area health service was determined using data from the 1996 ABS census, ${ }^{61}$ assuming an equal chance of each child being included in the survey. With different questions being asked of different age groups, the expected sample size for each age group was also determined (Table 9).

Wherever possible, it was decided to target questions to pre-schoolers aged 0-4 years and school-aged children 5-12 years.

There was concern about the potentially small sample sizes in the younger age groups, if a strictly random selection process was used. Piloting was used to determine whether the sampling process could be weighted to result in equal sized samples of children aged 0-4 years and children aged 5-12 years. Sampling for the first pilot was weighted to preferentially select children aged $0-4$ years from households that also included children aged 5-12 years (the ratio was $3: 1$ ). The second pilot had no

\section{TABLE 9}

ESTIMATED SAMPLE SIZE FOR AGE GROUPS IN THE NEW SOUTH WALES CHILD HEALTH SURVEY: WITHOUT WEIGHTING FOR AGE

\begin{tabular}{|lcl|}
\hline Age group (years) & $\begin{array}{l}\text { Estimated NSW } \\
\text { sample size }\end{array}$ & $\begin{array}{l}\text { Range of } \\
\text { estimated } \\
\text { sample size } \\
\text { for Area Health } \\
\text { Service }\end{array}$ \\
\hline $0-1$ & 601 & $31-40$ \\
$1-4$ & 2627 & $145-169$ \\
$5-12$ & 5272 & $293-323$ \\
\hline
\end{tabular}

\section{TABLE 10}

RESULTS OF WEIGHTING APPLIED TO PILOT 1 COMPARED TO NO WEIGHTING IN PILOT 2, NEW SOUTH WALES CHILD HEALTH SURVEY

\begin{tabular}{|crr|}
\hline Age (years) & $\begin{array}{c}\text { Pilot 1 Weighted } \\
\mathbf{N}=\mathbf{2 4 0}\end{array}$ & $\begin{array}{c}\text { Pilot 2 } \\
\text { Unweighted } \\
\mathbf{N}=\mathbf{2 5 1}\end{array}$ \\
\hline 0 & $17(17.3)$ & $29(28.7)$ \\
1 & $23(23.5)$ & $17(16.8)$ \\
2 & $20(20.4)$ & $17(16.8)$ \\
3 & $22(22.5)$ & $20(19.8)$ \\
4 & $16(16.3)$ & $18(17.8)$ \\
Subtotal 0-4 & $98(40.8)$ & $101(40.2)$ \\
5 & $18(12.7)$ & $23(15.3)$ \\
6 & $20(14.1)$ & $11(7.3)$ \\
7 & $16(11.3)$ & $17(11.3)$ \\
8 & $16(11.3)$ & $20(13.3)$ \\
9 & $15(10.6)$ & $13(8.7)$ \\
10 & $18(12.7)$ & $18(12.0)$ \\
11 & $20(14.1)$ & $30(20.0)$ \\
12 & $19(13.4)$ & $18(12.0)$ \\
Subtotal 5-12 & $142(59.2)$ & $150(59.8)$ \\
Total 0-12 & $240(100.0)$ & $251(100.0)$ \\
\hline
\end{tabular}

weighting. Table 10 indicates that the weighting used in the first pilot did not substantially increase selection of children aged 0-4 years compared to no weighting. The weighting method used oversampled children aged 0-4 years, who lived in households with children aged 5-12 years; however, many households have children only aged 0-4 years or 5-12 years. Also, children aged 0-4 years who lived in households with older children may be systematically different from those who do not, so oversampling these children may have introduced bias. Based on these results, it was decided not to weight the sampling for the final survey.

\section{Initial household contact}

The process of contacting households and selecting survey respondents is outlined in Figure 2. The initial household contact was the first person to answer the telephone call. Two introductory questions were piloted to determine the ability to transfer the interview between the initial household contact and the proxy respondent (a person who was selected to respond to the survey on behalf of the randomly selected child). When contacting a household, interviewers initially asked to speak to 'a parent or carer of any children in the household' or to 'speak to someone aged 16 years or over'. This person was asked to provide information on the number of children, if any, aged 0-12 years in the household to allow random selection of a child from each household.

The two introductory questions did not vary the response rate. However, a higher proportion of mothers than fathers 


\section{FIGURE 2}

FLOW CHART OF RESPONDENT SELECTION FROM POINT OF INITIAL HOUSEHOLD CONTACT, NEW SOUTH WALES CHILD HEALTH SURVFEY

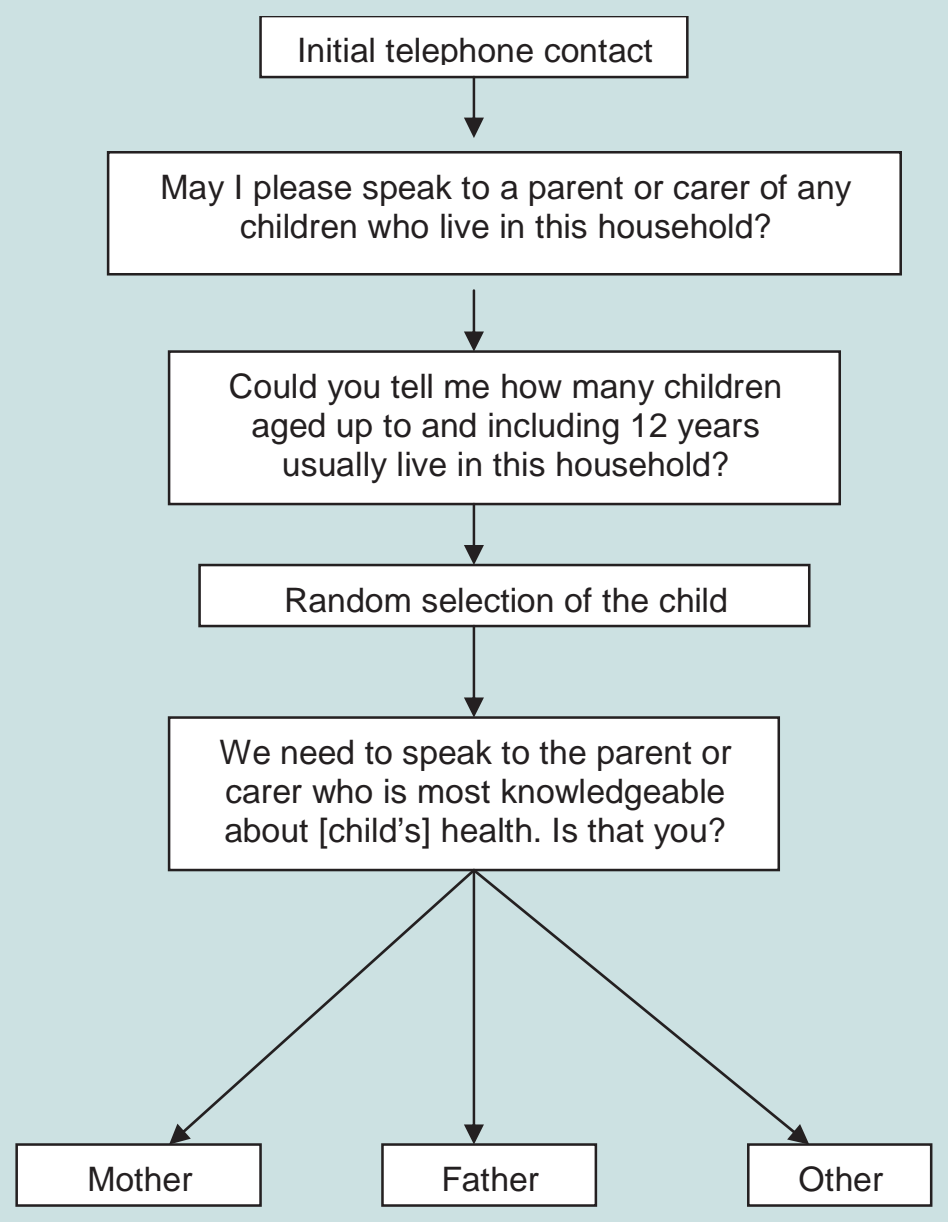

were requested by the household contact to come to the phone in response to the interviewers requesting to 'speak to a parent or carer', which lessened the need for a second handover to the chosen proxy respondent, as most proxy respondents were mothers. Given this result and the simplicity of asking to speak to a parent at initial contact, it was decided to use this question.

\section{The proxy respondent}

Issues concerning the selection of the proxy respondent who would provide the most accurate and detailed information on the child's health and wellbeing were debated at length and included:

- potential for differences in response between male and female respondents;

- difficulty of preferentially requesting child's mother to be proxy respondent;
- selecting the person who knows the most about the child's health;

- the need to select the child first and then the proxy respondent.

The results of a number of children's surveys were reviewed to determine the types of proxy respondent. The Auburn Health Study involved a random sample of 811 English-speaking respondents, via an electronic telephone directory, of which 189 were by proxy interview with the main caregiver because the selected respondent was aged $0-17$ years. Of the proxy interviews, 58 per cent of all proxies were the child's mother, 34 per cent were fathers, four per cent were sisters, two per cent brothers, two per cent uncles, and one per cent grandmothers. ${ }^{62}$ In the Western Sydney Area Health Service Pneumococcal Study in NSW, the main caregiver was also asked to complete the survey; only 15 per cent of proxy respondents were fathers. ${ }^{49}$ 
A review of the literature regarding use of proxy respondents in child surveys did not highlight any preferred methods of recruiting them. In most studies 75 per cent or more proxy respondents were mothers. The difference between fathers, mothers, and other carers as proxy respondents was not critically reviewed.

Two different questions were piloted to see if they would produce different results in the selection of proxy respondent - mother, father, grandparent or other carer. The first question was 'can I speak to the person who knows most about the [selected] child's health?', and the second was 'can I speak to the person who takes the [selected] child to the doctor?' (Table 11).

The first pilot showed that most (73.8 per cent) proxy respondents were mothers, 20.8 per cent were fathers and 5.4 per cent were other types including grandparents, stepparents and legal guardians. There was little difference between the two questions, in terms of eliciting a response from different proxies, except the question 'the person who takes the child to the doctor' elicited a higher proportion of mothers as proxy respondent (75.4 per cent compared with 72.1 per cent). In the second pilot, using the same questions, 83.7 per cent of proxy respondents were mothers, 10.0 per cent fathers and 6.4 per cent other types. In contrast to the first pilot, the question 'the person who knows the most about the child's health' elicited a higher proportion of mothers who were proxies (84.8 per cent compared with 82.5 per cent). The question seeking 'the person who knows most about the child's health' was preferred by the CHSTEG as it was felt that it would be more likely to exclude family members other than parents or unrelated carers such as nannies when the parents were available.

In the 'other' proxy respondent category, it was common for the child to live with only one parent (four out of five). Of the proxy respondents who were fathers, 45 of 50 (90.0 per cent) in the first pilot and 21 of 25 ( 84.0 per cent) in the second pilot reported the child also lived with its mother.

\section{Question response}

Piloting showed that several questions elicited responses clustered at one end of the measurement scale (floor or ceiling effect). One example of this was the questions on immunisation. Initially it was proposed that immunisation questions include:

- Has child ever received any of the recommended childhood vaccinations?

- To which health professionals have you ever taken child to be vaccinated?

- As far as you are aware is child up to date with vaccinations?

- Can you tell me the reasons child [is not up to date]has not had any vaccinations?

- Overall, how do you feel about childhood vaccination? Do you strongly support...?

- What has influenced your views about vaccination?

- In what ways have your views been influenced? Are you more supportive, less supportive...?

Of 98 respondents aged two months to four years in the first pilot, 91 (92.9 per cent) reported the child having ever been vaccinated. The most common provider for vaccination was a medical practitioner (69 per cent of all ever used providers). Interestingly, 90 of 91 (98.9 per cent) reported their child was up to date with vaccinations, much higher than reported in other immunisation data sources. Most respondents reported being supportive of vaccination (94.5 per cent). The most common influences on views about vaccination were media (38 per cent) followed by personal experience. Overall 83 people $(91.2$ per cent) reported being more supportive of vaccination.

The high ceiling effects observed for some of the immunisation questions limited their usefulness. Based on these results, only three immunisation questions were included in the final survey: 'to which health professionals or places have you ever taken child to be vaccinated?'; 'overall, how do you feel about childhood vaccination? Do you strongly support?; and 'from which sources have you received information about vaccination?'

\section{TABLE 11}

PROXY RESPONDENT SELECTED BY DIFFERENT QUESTIONS USED INTWO SURVEY PILOTS, NEW SOUTH WALES CHILD HEALTH SURVEY

\begin{tabular}{|c|c|c|c|c|c|c|}
\hline \multirow[t]{2}{*}{ Proxy respondent } & \multicolumn{3}{|l|}{ Pilot 1} & \multicolumn{3}{|l|}{ Pilot 2} \\
\hline & $\begin{array}{l}\text { '...the person } \\
\text { who knows the } \\
\text { most about the } \\
\text { child's health?' }\end{array}$ & $\begin{array}{l}\text { '...the person } \\
\text { who takes the } \\
\text { child to the } \\
\text { doctor?' }\end{array}$ & Total & $\begin{array}{l}\text { '...the person } \\
\text { who knows the } \\
\text { most about the } \\
\text { child's health?' }\end{array}$ & $\begin{array}{l}\text { '...the person } \\
\text { who takes the } \\
\text { child to the } \\
\text { doctor?' }\end{array}$ & Total \\
\hline Mother & $88(72.1)$ & $89(75.4)$ & 177 (73.8) & $106(84.8)$ & $104(82.5)$ & 210 (83.7) \\
\hline Father & 27 (22.1) & 23 (61.9) & $50(20.8)$ & $11(8.8)$ & $14(11.1)$ & $25(10.0)$ \\
\hline Other & $7(5.7)$ & $6(5.1)$ & $13(5.4)$ & $8(6.4)$ & $8(6.3)$ & $16(6.4)$ \\
\hline Total & $122(100.0)$ & $118(100.0)$ & $240(100.0)$ & $125(100.0)$ & $126(100.0)$ & $251(100.0)$ \\
\hline
\end{tabular}




\section{Interviews in languages other than English}

Translation methods were in keeping with other NSW Health Surveys. ${ }^{5}$ The language groups considered eligible were those most common for parents of children aged 0 12 years in NSW. Given the resources required for translation and interviews in languages other than English (LOTE), an estimated minimum of 20 interviews in a specific language group was required to include a language group in the translation process.

An estimate of the number of interviews in LOTE was determined using the following information from the 1996 ABS Census for each area health service:

- the proportion of women aged 19-54 years whose English language proficiency was categorised as 'poor' or 'not able to speak English'. ${ }^{61}$ Women aged 19-54 years were used as the most likely proxy respondents for children aged $0-12$ years, and their language skills tend to be less proficient than men; ${ }^{61}$

- the 10 most common languages other than English for women aged 19-54.

The estimated number of interviews in each language group was summed and ranked for NSW as a whole. Since the 1997 NSW Health Survey of adults had a far higher number of LOTE interviews than predicted from ABS language proficiency data, ${ }^{22}$ the actual versus the estimated number of interviews in each language was calculated to produce a factor. This factor was then multiplied by the initial estimated number of interviews in LOTE to give a more accurate idea of how many interviews would actually be conducted in LOTE (Table 12).

Based on the results in Table 12, and the inclusion criteria, it was decided to conduct the survey in three languages other than English: Chinese, Vietnamese, and Arabic.

\section{Collecting information on other carers of children in the household}

Children's health is influenced by the broader family and socioeconomic environment, so it was important to include demographic questions about the child's parents. However the dilemma was whether to collect information about parents who were not the proxy and whether information on step-parents would also be useful. One issue this raised was the willingness of the proxy respondent to report information on the child's other parent, particularly when the other parent was residing elsewhere. It was decided to obtain information about the parents or carers that had a major influence over the child. The proxy respondent was asked for information about their socioeconomic circumstances and that of the child's other parent-carer if the child lived with that parent-carer or spent a reasonable amount of time with that parent on a regular basis.

\section{Order and timing of questions}

Telephone interview duration can affect response rates. ${ }^{63}$ It was important to test the time it would take for different age groups to complete the survey, so interviewers could accurately inform respondents regarding interview duration. The mean time to conduct the first pilot varied by age group, with interviews about children aged $0-1$ years taking 22 minutes, children aged $2-4$ years taking 25 minutes, and children aged 5-12 years taking 33 minutes. In the second pilot, children aged 0-2 years had the shortest mean survey completion time of 26 minutes, children aged 3-4 years were 28 minutes, and children aged 5-12 years took an average of 32 minutes (Table 13). Timing of various question modules was measured for pilot two. The longest module for the children aged 5-12 years was The Child Health Questionnaire, taking 5 minutes and 41 seconds.

\section{TABLE 12}

ESTIMATED NUMBERS OF INTERVIEWS IN LANGUAGES OTHER THAN ENGLISH (LOTE) FOR THE NEW SOUTH WALES CHILD HEALTH SURVEY

\begin{tabular}{|c|c|c|c|}
\hline Language group & $\begin{array}{l}\text { Est. No. interviews } \\
\text { Based on language } \\
\text { proficiency of women } \\
\text { aged } 19-54\end{array}$ & $\begin{array}{l}\text { Percentage women aged } \\
19-54 \text { years with poor } \\
\text { English language } \\
\text { proficiency (ABS census) }\end{array}$ & $\begin{array}{l}\text { Estimated number of } \\
\text { interviews after } \\
\text { weighting based } \\
\text { on results of } 1997 \text { NSW } \\
\text { Health Survey }\end{array}$ \\
\hline Chinese & 46 & 20 & 119 \\
\hline Vietnamese & 26 & 43 & 51 \\
\hline Arabic & 18 & 15 & 39 \\
\hline Korean & 10 & 47 & $20^{*}$ \\
\hline Greek & 7 & 9 & 7 \\
\hline Spanish & 6 & 12 & $12^{*}$ \\
\hline Macedonian & 5 & 12 & 6 \\
\hline Italian & 4 & 5 & 3 \\
\hline
\end{tabular}




\section{TABLE 13}

MEAN DURATION OF VARIOUS SECTIONS OF THE NEW SOUTH WALES CHILD HEALTH SURVEY 2001 BY AGE GROUP PILOT TWO

\begin{tabular}{|c|c|c|c|}
\hline Content areas & $0-2$ years & $3-4$ years & $5-12$ years \\
\hline Demographics & $3 \mathrm{~min} 53 \mathrm{sec}$ & $3 \min 56 \mathrm{sec}$ & $3 \min 51 \mathrm{sec}$ \\
\hline Child Health Questionnaire & Not asked & Not asked & $5 \min 41 \mathrm{sec}$ \\
\hline Social Capital & $3 \min 2 \mathrm{sec}$ & $3 \min 26 \mathrm{sec}$ & $3 \min 6 \mathrm{sec}$ \\
\hline Sun Protection & Not asked & $2 \min 52 \mathrm{sec}$ & Not asked \\
\hline Family Functioning & $2 \min 9 \mathrm{sec}$ & Not asked & Not asked \\
\hline Subtotal of above sections & $9 \min 4 \mathrm{sec}$ & $10 \min 14 \mathrm{sec}$ & $12 \mathrm{~min} 38 \mathrm{sec}$ \\
\hline Mean duration of survey & 26 minutes & 28 minutes & 32 minutes \\
\hline
\end{tabular}

The time for survey completion for children aged 5-12 years was greater than the time advised to respondents in the survey introduction ( 25 minutes). It was therefore decided to remove selected questions for children aged 5-12 years in the modules of demographics, school, injury, and attendance at school and childcare.

\section{Introductory letters}

Providing randomly sampled households with a letter with information about the survey prior to telephone contact can improve response rates. ${ }^{64}$ However, there is a significant cost and organisational effort required to send letters to households included in the New South Wales Child Health Survey sample, since not all randomlyselected households have children aged 0-12 years. Therefore, the number of letters that needed to be sent was about six times the sample size. In the second pilot, households listed in the electronic White Pages were randomised to either receive or not receive a letter, to determine the effect of the letter on the response rate. These results are shown in Table 14.

It was decided that, even with the numerous ineligible households receiving the letter, the increase in response rate justified the expense. The inclusion in the letter of details of a ' 1800 number' to call for assistance not only gave respondents the opportunity to gain additional information but also allowed non-eligible households to

\section{TABLE 14}

EFFECT OF MAILING LETTER ABOUT SURVEY ON THE RESPONSE RATE, PILOT 2

\begin{tabular}{lc} 
Sample sub-groups (\%) & Response rate \\
\hline Household in white pages, letter sent & 76 \\
Household in white pages, no letter & 66 \\
Household not in white pages, no letter & 70
\end{tabular}

inform the NSW Health Survey Program that they had no children in their household.

\section{Identification of children at risk}

Following submission of the final survey to the NSW Department of Health's Human Research Ethics Committee, concerns about child protection issues were raised. The survey included questions on issues such as child behaviour, child feeding, and food security, and it was deemed possible that during the interview these sensitive questions could result in parents disclosing circumstances that may warrant referral to support agencies or other appropriate services.

With these concerns in mind, representatives from the NSW Department of Community Services met with the NSW Department of Health to develop procedures for use where a child was deemed at risk of being harmed, or had been harmed.

First, the questions that may trigger replies alerting a need for parental support were identified. In the event of suspected child abuse or neglect, a written procedure (Box 1) and flow chart (Figure 3) were developed to determine the protocol for referral to support services. The flow chart included steps for the provision of information regarding parental support, and steps for informing parents of issues that might indicate a notification is required.

Supervisors and management staff received specially adapted training on child protection issues from the Child Protection Trainer at NSW Department of Health's Education Centre against Violence.

Continued on page 38 


\section{FIGURE 3}

\section{CHILDREN AT RISK FLOW CHART}

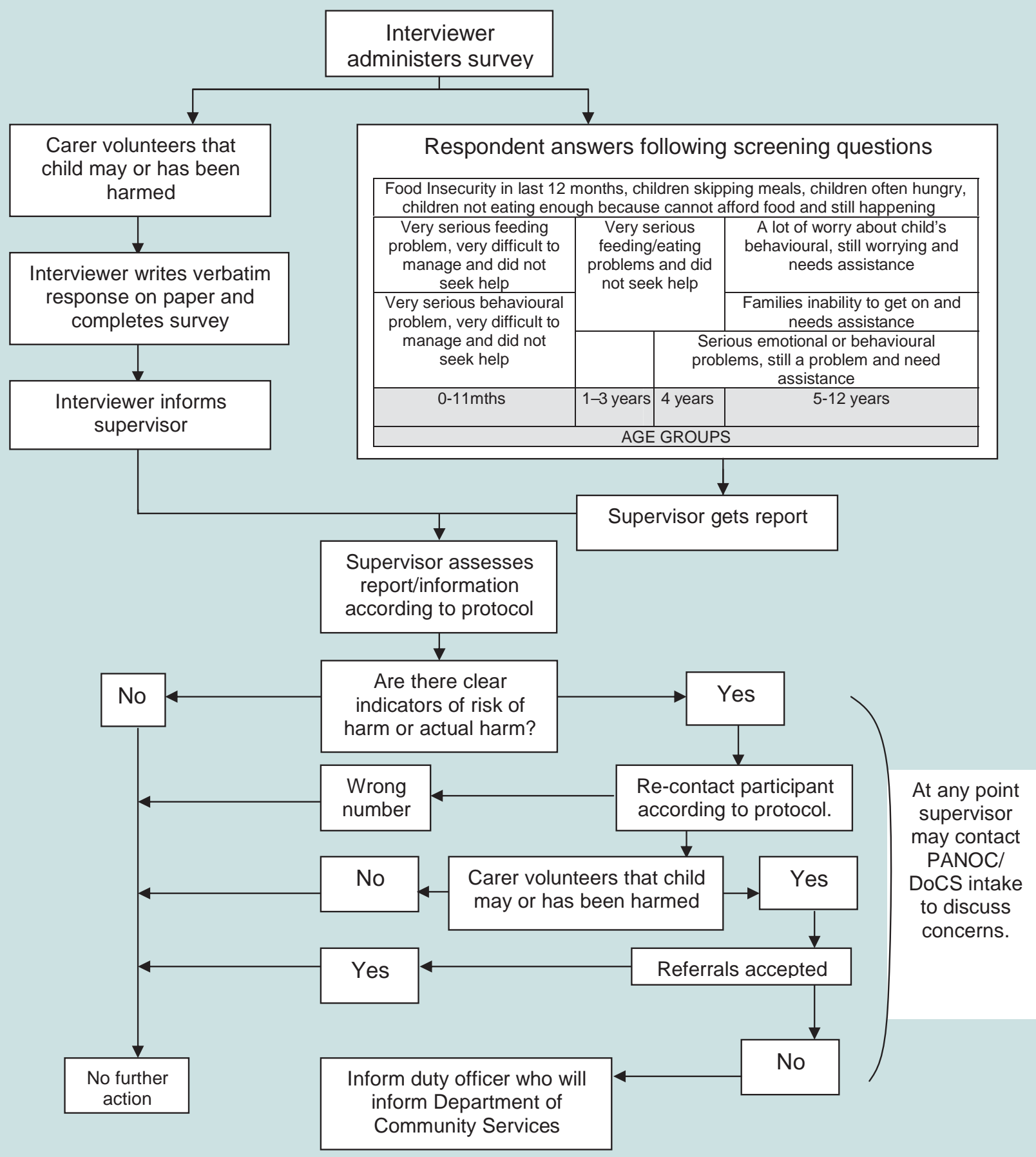




\section{BOX 1}

\section{CHILD HEALTH SURVEY CHILD PROTECTION PROCEDURES}

Employees of NSW Health are directed by the DirectorGeneral in Circular $97 / 135$ to notify to the Department of Community Services if they suspect a child is at risk of harm or abuse.

Supervisors of Child Health Survey Interviewers will:

- follow the steps outlined in the procedures and flowchart

- attend child protection training provided by Education Against Violence,

- discuss child protection concerns with Central Sydney Physical Abuse and Neglect of Children (PANOC) coordinator and/or Inner West Child Protection Specialist.

At any point the supervisor may contact the PANOC coordinator to discuss concerns.

Any interagency or procedural child protection issues will be brought to the attention of the Manager, Health Services

Policy Branch to ensure that these issues are addressed in a comprehensive and timely fashion.

The procedure will be used in the following circumstances: If participants provided responses to a group of questions that would indicate need for parental support

If participants in the course of the survey stated that any member of the household were at risk of harming or had harmed the child.

It was agreed that should these events arise, the interviewer would report to the supervisor, or the supervisor would automatically receive report from the database if monitoring questions were being highlighted. The supervisors of the Child Health Survey will receive training in recognition and notification of child abuse, provided by NSW Health.

A daily report would be prepared for the supervisor if the following outcomes were collected:

Child age $=0-11$ months and Food Security and Feeding Problems and Behaviour problems.

Child age $=1-4$ years and Food Security and FeedingEating Problems and Behaviour problems.

Child age $=5-12$ years and Food Security and Family Ability to get along and Behaviour problems and parent worried about Child Behaviour.

These outcomes on their own do not indicate risk of harm to the child, but may suggest that the child may be of higher risk, and the family may require further support.

In the event of suspected child abuse or neglect, the supervisor would re-contact the participant, in order to discuss concerns and offer further support. The supervisor would also inform the participant, of their duty to notify, should they intend to contact the Department of Community Services.

Department of Community Services and NSW Health have agreed to provide a contact person to the Manager and Supervisor of the New South Wales Child Health Survey to discuss child protection issues as they arise during the administration of the survey.

\section{BOX 2}

\section{SCRIPT USE FOR INFORMED CONSENT FOR PARENTS OR CARERS OF CHILDREN IN THE NEW SOUTH WALES CHILD HEALTH SURVEY}

Your help with this survey is voluntary. All that is involved is answering some questions about [child's] health, wellbeing and use of health services. The survey takes around 25 to 30 minutes for most people but may take a little longer in some cases. There are no 'right' or 'wrong' answers to any of the questions. You can stop at any time or simply refuse to answer a question should you prefer.

Please be assured that all the answers to questions remain completely confidential, except where you volunteer information that we are required to report by law.

[PROMPT IF NECESSARY: All the answers that you give to the questions remain completely confidential. However if you tell us additional information about breaking the law or that suggests a child is being abused or neglected, then we are required to report this to the appropriate authority such as the NSW Department of Community Services.]

The information from this survey will be used to help improve health services for children in your area and across the state, so your help is very important to us.

Are you willing to help us with the survey?

The Ethics Committee also stipulated that a number of changes were to be made to the informed consent including stating that the NSW Health Survey Program are required to report by law to the appropriate authority, if additional information suggests a child is being abused or neglected (Box 2).

There was considerable concern that the inclusion of this statement would affect the response rate-possibly to such an extent that conduct of the survey could not be justified. In order to test the effect of this statement, a third pilot study was conducted and it was found that the statement did not affect the response rate, first pilot $(N=240,72$ per cent) compared to second pilot ( $N=251,76$ per cent). 